
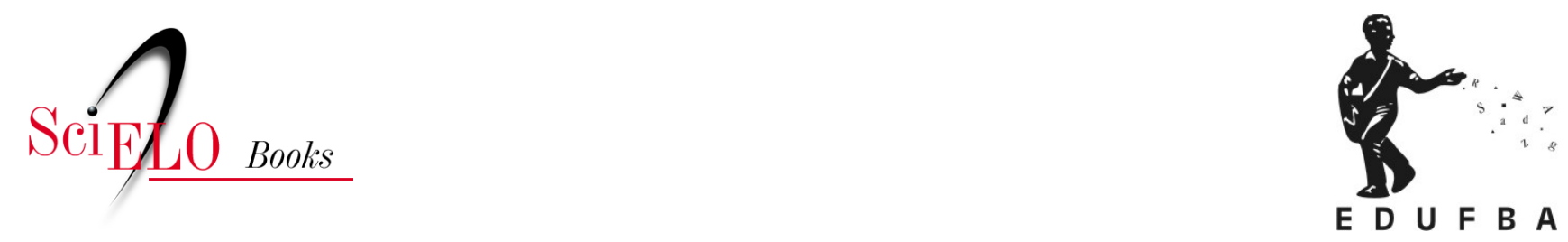

\title{
Apêndice $C$ \\ Concepções acerca do conceito de homens que fazem sexo com homens
}

\author{
Sandra Garrido de Barros
}

\section{SciELO Books / SciELO Livros / SciELO Libros}

BARROS, S.G. Apêndice C - Concepções acerca do conceito de homens que fazem sexo com homens. In: Política Nacional de Aids: construção da resposta governamental à epidemia HIV/aids no Brasil [online]. Salvador: EDUFBA, 2018, pp. 311-312. ISBN 978-85-232-2030-3.

https://doi.org/10.7476/9788523220303.0011.

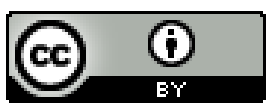

All the contents of this work, except where otherwise noted, is licensed under a Creative Commons Attribution 4.0 International license.

Todo o conteúdo deste trabalho, exceto quando houver ressalva, é publicado sob a licença Creative Commons Atribição $\underline{4.0}$. 


\section{APÊNDICE C \\ Concepções acerca do conceito de homens que fazem sexo com homens}

Continua

\begin{tabular}{|c|c|c|}
\hline $\begin{array}{l}\text { Campo/ } \\
\text { Espaço }\end{array}$ & Agente & Conceito HSH \\
\hline \multirow[t]{3}{*}{ Científico } & E16 & $\begin{array}{l}\text { Esse é um termo que vem dos Estados Unidos e é muito da saúde pública, por entender que vários } \\
\text { homens que se identificam nas suas práticas sexuais como héteros, eles têm relações com outros } \\
\text { homens e não se identificam nem como homo, nem como bi, eles se identificam como hétero. Então, } \\
\text { como incluir essas pessoas na prevenção? [...] Se a gente esta fazendo políticas públicas de saúde, } \\
\text { se a gente esta falando de saúde coletiva, temos que ampliar a base para prevenção. [...] e que hoje } \\
\text { algumas pessoas falam em chamar de "gays, bissexuais, e outros HSH". Até isso tem sido usado, } \\
\text { porque o movimento gay afirma que a identificação gay [...], ela é política e ela é importante [...] E } \\
\text { para prevenção [...], a mensagem seria um pouco diferente. }\end{array}$ \\
\hline & E19 & $\begin{array}{l}\text { [...] eu aprendi que não é só politicamente correto dizer homens que fazem sexo com homens ao } \\
\text { invés de homo ou bissexuais e sim porque eu recrutava caminhoneiros por exemplo. Vai dizer para } \\
\text { um caminhoneiro, ele é tão macho que come até viado na estrada, vai dizer para ele que ele é } \\
\text { homossexual. Então, homem que faz sexo com homem, não necessariamente entrar na sigla de ser } \\
\text { um gay. Eram só homo e bissexuais. }\end{array}$ \\
\hline & E25 & $\begin{array}{l}\text { Eu acho que ele tem potencialidade que ele inclui pessoas que não se vêem como homossexuais. Por } \\
\text { outro lado ele tem limitações, porque as seletivas não se incluem nesses temas.[...] Eu não sei quem } \\
\text { desenvolveu, mas quem traz para cá é o pessoal da Abia, em geral. Que é tudo fruto dos estudos sobre } \\
\text { homossexuais do Peter Fry e do Edward [MacRae]que vai ver essas relações no Brasil, como é que a } \\
\text { cultura popular daqui lida com isso. }\end{array}$ \\
\hline \multirow[t]{2}{*}{ Médico } & $E 23$ & $\begin{array}{l}\text { [...] são pessoas que não tem a identidade com o movimento homossexual, com a identidade gay, } \\
\text { mas tem relações homoeróticas. E o problema dessas pessoas é que elas não se enxergam sob risco. } \\
\text { Na medida em que você só coloca homossexual e você não fala de homem que faz sexo com homem, } \\
\text { você está tirando do grupo de risco, do comportamento de risco, essa relação sem identificação. } \\
\text { Então eu acho que o benefício que tem essa nomenclatura é isso, é colocar pessoas que não se auto- } \\
\text { identificam como passíveis de se contaminar. }\end{array}$ \\
\hline & E31 & $\begin{array}{l}\text { [...] eu acho que às vezes se perde muito tempo nessas questões. Mas no final elas tem a questão } \\
\text { da identificação. Se você refere com o termo errado, faz uma pergunta... principalmente quando a } \\
\text { gente está estudando comportamento. Eu acho que é um desafio hoje, na questão da prevenção, você } \\
\text { conseguir mapear isso [...] Se você faz a pergunta errada pode ser um problema. }\end{array}$ \\
\hline Burocrático & E2 & $\begin{array}{l}\text { [...] o machão brasileiro acha que o homem só é considerado homossexual se ele for passivo durante a } \\
\text { relação sexual, [...] então essa ideia de homens que fazem sexo com homens,[...] é para desconstruir } \\
\text { essa ideia que é muito forte no imaginário, por exemplo, um homem casado que se relaciona com } \\
\text { outro homem, mas que sempre assume digamos, sei lá, que ele acha que está assumindo uma } \\
\text { posição muito, entre aspas, ativa na relação sexual, ele acha que não é homossexual e acha que não } \\
\text { tem risco e acha que não precisa usar preservativo com a mulher. }\end{array}$ \\
\hline
\end{tabular}




\begin{tabular}{|c|c|c|}
\hline $\begin{array}{l}\text { Campo/ } \\
\text { Espaço }\end{array}$ & Agente & Conceito HSH \\
\hline \multirow[t]{4}{*}{$\begin{array}{l}\text { Espaço } \\
\text { Militante }\end{array}$} & E12 & $\begin{array}{l}\text { Tem-se muita dificuldade em fazer campanhas especificas para gay, porque começou a partir daí a } \\
\text { ter uma compreensão muito grande que tu não fala apenas para o gay, você fala para o gay, para } 0 \\
\text { travesti, para o transexual, para o homem que faz sexo com homem que se diz não gay. Isso abriu } \\
\text { um leque de linguagens entre o movimento. No momento falava viado, bicha e hoje você fala HSH, } \\
\text { que engloba tudo. [...] que são homens que fazem sexo com homens mas [...] que não se auto } \\
\text { denominam gays. [...] que poderia ser até bissexual, no caso, que não se define como homossexual, } \\
\text { mas que teria práticas homossexuais. }\end{array}$ \\
\hline & E14 & $\begin{array}{l}\text { A gente passou por um período no movimento de aids, que a gente começou a entrar nessa dinâmica } \\
\text { de querer mudar as terminologias, as palavras, porque as palavras poderiam carregar consigo o } \\
\text { preconceito, o estigma e também fechar determinados grupos quando você não se sentia parte } \\
\text { daquele grupo, você poderia também não se sentir vulnerável e não exercer a sexualidade mais } \\
\text { segura, responsável e com a prevenção. Então, para os homossexuais foi HSH, para as prostitutas } \\
\text { trabalhadoras sexuais, e população que antes era só gays agora é LGBTs que é enorme... Com tantas } \\
\text { siglas, tantas letras, e depois houve todo um retrocesso, um retrocesso não, um repensar nisso e a } \\
\text { população gay passou a deixar de lado, os profissionais que trabalham com aids deixaram de lado o } \\
\text { HSH e voltaram a falar população gay. As prostitutas não queriam usar mais o termo trabalhadoras } \\
\text { sexuais e sim prostitutas, porque há uma força política nisso também, construção de identidade }\end{array}$ \\
\hline & E20 & $\begin{array}{l}\text { [...] uma despolitização da homossexualidade. Nós consideramos que mesmo aqueles indivíduos, } \\
\text { eu já escrevi isso: HSH, um conceito equivocado epidemiologicamente e politicamente, porque o } \\
\text { machão, o bissexual que transa com o travesti ou com a bicha, ele não considera que seu parceiro } \\
\text { é um homem. É uma bicha ou uma travesti. E ele próprio, embora não se considere homossexual, } \\
\text { ele tem a consciência de que ele está praticando um ato homossexual. A categoria HSH não ajuda } \\
\text { ninguém, nem a prevenção junto aos próprios bissexuais, nem aos próprios bichas e travestis que } \\
\text { não se consideram homens muitas delas, de modo que nós protestamos e que até hoje ainda existe } \\
\text { alguém que defenda, mas é uma forma equivocada como a experiência demonstrou. }\end{array}$ \\
\hline & E33 & $\begin{array}{l}\text { A gente aqui da Abia foi acusada de embates e confusões com o Mott como se a gente quisesse } \\
\text { desmobilizar a identidade política proposta pelos grupos gays organizados. E na verdade não tem } \\
\text { nada disso porque a gente usa em geral HSH e gay indiscriminadamente. A gente usa até HSH, gay, } \\
\text { homossexuais, depende de como as pessoas se identifiquem. A gente não pode negar que existe um } \\
\text { mundo de homens que tem uma prática homossexual e que não tem uma identidade homossexual. } \\
\text { Não somos nós que vamos dizer que eles são gays não assumidos. Se o movimento homossexual } \\
\text { queira classificar assim é legítimo. Eu mesmo pessoalmente posso achar isso, mas eu não posso } \\
\text { dentro de um programa de prevenção da aids achar essas coisas. Eu tenho que trabalhar com essas } \\
\text { diferenças e com um relato do que as pessoas falam. É uma categoria complicada, eu admito, } \\
\text { politicamente [...], mas por outro lado dá conta de uma série de diferenças que existem dentro } \\
\text { das relações homossexuais e que precisam ser consideradas no trabalho de prevenção. Mas é uma } \\
\text { categoria complicada, sem dúvida. }\end{array}$ \\
\hline
\end{tabular}

